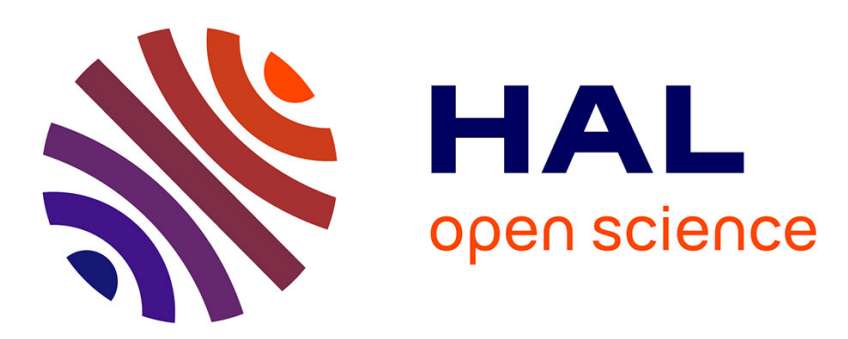

\title{
Trend and Comparative Analysis of Inequality of Social Opportunity
}

\author{
Nathalie Bulle
}

\section{To cite this version:}

Nathalie Bulle. Trend and Comparative Analysis of Inequality of Social Opportunity. Quality \& Quantity, 2006, 40, pp.129-143. halshs-00137185

\section{HAL Id: halshs-00137185 \\ https://shs.hal.science/halshs-00137185}

Submitted on 17 Mar 2007

HAL is a multi-disciplinary open access archive for the deposit and dissemination of scientific research documents, whether they are published or not. The documents may come from teaching and research institutions in France or abroad, or from public or private research centers.
L'archive ouverte pluridisciplinaire HAL, est destinée au dépôt et à la diffusion de documents scientifiques de niveau recherche, publiés ou non, émanant des établissements d'enseignement et de recherche français ou étrangers, des laboratoires publics ou privés. 


\title{
TREND AND COMPARATIVE ANALYSIS OF INEQUALITY OF SOCIAL OPPORTUNITY
}

\author{
Version 1.2 \\ Nathalie Bulle, 2006, « Trend and Comparative Analysis of Inequality of Social \\ Opportunity », Quality \& Quantity, 40 : 129-143.
}




\section{TREND AND COMPARATIVE ANALYSIS OF INEQUALITY OF SOCIAL OPPORTUNITY}

This article sets out a new method for the analysis of inequality of social opportunity. The shortcomings of the previous concepts and measures attempting to assess the degree of openness of the mobility process independently of marginal effects are displayed. The suggested new approach refers to relative opportunity distributions of individuals according to their social origin. Starting from the premise that these distributions underlying the observed allocation of social positions are continuous, it is assumed that it is possible to compare them using straight lines. The various slopes of the lines represent inequality of social opportunity coefficients which permit trend and comparative analysis of the mobility process net results. 


\section{Trend and comparative analysis of inequality of social opportunity}

\section{Introduction}

Sociologists have long striven to distinguish two types of social mobility: 'structural' mobility and 'exchange' or 'circulation' mobility. The notion of structural mobility refers to the changes in status forcibly brought about by the differences in size of origin and destination categories. On the other hand, the notion of exchange or circulation mobility refers to mobility that arises from the intrinsic openness of the mobility process. Sociologists have attempted to control for marginal effects (structural mobility) because they sought to assess, in a comparative perspective, the importance of the redistribution of social privileges attributed to the social processes at work. While this framework has largely been abandoned, the aim of appraising the intrinsic degree of openness of societies is still alive and needs conceptual clarity.

The following sets out to review briefly the major models developed thus far, as well as the problems they raise. A new approach is then proposed, based on the characterization of relative opportunity distributions of individuals according to their social origin. Starting from the premise that these distributions underlying the observed allocation of social positions are continuous, it is assumed that it is possible to compare them using straight lines. The various slopes of the lines represent inequality of social opportunity coefficients which permit trend and comparative analysis of the mobility process net results.

\section{Principal concepts and models}

\subsection{From 'mobility ratios' to 'odds ratios'}

Contemporary research on social mobility has been developing since the late 1940s. More specifically, it dates back to the analyses carried out by Rogoff (1953) and Glass (1954), who sought to qualify the influence of social origin on social destination despite the differences in size among the various social categories and among the distributions of these categories from one generation to another. They introduced the concept of 'mobility ratio' or 'index of association', which is the ratio of frequency 
observed in a given cell in the mobility table under consideration $\left(f_{i j}\right)$ to the expected frequency in the case of statistical independence $\frac{n_{i .} \times n_{. j}}{N}$. This index $f_{i j} \times \frac{N}{n_{i .} \times n_{. j}}$ was favored in comparative studies as it was the only measurement making international comparisons possible (Miller 1960). However, various critical commentaries have shown its limits (Billewicz 1955 ; Yasuda 1964 ; Blau and Duncan 1967, Tyree 1973). In particular, the values of the association indices vary within intervals depending on the margins $n_{i}$. et $n_{. j}$. Measurements set up in order to control for structural mobility and assess the intrinsic openness of the mobility process were later refined (Matras 1960; Yasuda 1964; Boudon 1972, 1973; Persson 1977).

The fact that changes in occupational structure necessarily affect the types of relationship among social strata is a limit inherent to the pursuit of 'pure' mobility (Noble 1979; Goldthorpe 1980: 74, 88, 2000; Cherkaoui 2003). Measurement of rates of exchange between social categories, 'all other things being equal' - i.e. by controlling for the mobility which is forced out by discrepancies in occupational structure - means making an artificial distinction between forced individual mobility (calculated on the basis of the differences between marginal distributions) and free individual mobility (calculated on the basis of equal marginal distributions), which make it difficult to interpret the rate of 'free' mobility measured ${ }^{1}$. In addition, the marginal distribution of social origins in a mobility table does not represent an occupational distribution at any prior point in time (Duncan 1966). As suggested by Duncan, it is better to consider the intergenerational mobility matrix not as information on mobility but as information on the dependence of sons' statuses on fathers' statuses.

Given the conceptual problems of distinguishing 'structural' and 'circulation' mobility, the nonproblematic concepts of 'absolute' and 'relative' rates of mobility have been preferred. The latter are in the form of odds ratios and measure 'social fluidity'. Second-order odds ratios ${ }^{2}$ have proved to be of particular interest because they are, though in a limited sense, 'insensitive' to margins ${ }^{3}$. Techniques based on odds ratios such as log-linear modeling of contingency tables ${ }^{4}$ are now universally applied in social mobility research ${ }^{5}$.

This change in conceptual orientation has been accompanied by a change in the type of social process results which were to appraise. Sobel (1983) pointed out that log-linear models cannot be used to partition mobility into structural and circulatory components which earlier research had attempted to discern because associations in a mobility table cannot be equated with the concept of 'circulation' mobility. However the key point is not yet well established in the literature: odds ratios do not control for 'forced' mobility. Arguments put forward developed the idea that proportional adjustment does not control for the availability of positions. In other words, odds ratios significance in relation to the social 
selection process is not independent of margins: changes in the proportions selected for various social destinations or in selected class boundaries will affect the measured relationship between selection and stratification (Blackburn and Marsh 1991: 517). Thus great care must be exercised when drawing conclusions from analyses of odds ratios (Harrison 1988, Blackburn and Prandy 1997). On the basis of classic models of mobility processes from which contingency tables may be drawn up, such as vacancy models and Markov models, it appears that changes in marginal distributions cause variations in odds ratios, whereas the processes themselves remain stable, thus showing the ambiguity of such variations (Sorensen 1977, Harrison 1988).

\subsection{Major classical approaches shortcomings}

The solutions developed to account for the intrinsic openness of the mobility process were based either on the notion of 'exchange' or 'circulation' mobility (defined in opposition to mobility caused by changes in the occupational distribution of the labor force) or on indices of association (defined in opposition to the state of statistical independence between social categories of origins and destinations). They share one feature which accounts for their respective shortcomings. The notion of exchange stands in opposition to that of non exchange, i.e. reproduction, as the notion of association measures the rigidity of the mobility process by the connections observed between social categories. In other words, these measures assess the degree of openness of the mobility process on the basis of relationship between origin and destination social categories: the analytical framework used opposes these categories in a perspective which is de facto that of sociology of conflict. This representation is ill suited to a relatively open society in which the mobility process is not structured by reproduction of status patternsi.e. the results of the selection process tend rather to follow a model of 'meritocratic' classification of individuals and allocation of positions according to availability.

Distribution of social opportunity into social categories creates the difficulties of interpretation discussed above:

- either rates of exchange between categories are measured with artificial equal marginal distributions in view of controlling for forced mobility; in which case the significance of the rate of exchange mobility is hard to interpret ;

- or measurement of the association links between origin and destination categories is based on selection requirements which vary with the distribution of destination categories, in which case it does not allow assessment of inequality of opportunities in the selection process. 
A response to these problems is to define the social opportunities of individuals on the basis of an opportunity scale with equal distances from top to bottom at all points of time. As this scale provides a fixed reference point from one population to the next with respect to opportunity, its meaning is independent of structural changes in the stratification system. In addition it expresses the idea of vertical mobility which remains at the basis of the concept of inequality of social opportunity ${ }^{6}$. McClendon (1977) offers a solution based on the use of standardized prestige scales and the analysis of regression. However, this model is limited in its application, notably because of use of non-classical stratification categories ${ }^{7}$. A new method is proposed in this paper which does not rely on a detailed ranking of occupations. One has not to assume that the stratification order is continuous in nature. As shown below, the key point is that relative opportunity distributions of individuals from various social groups may be evaluated using continuous models.

\section{Analysis of relative social opportunity distributions of individuals according to their social} origin

\subsection{Definition of continuous opportunity distributions}

It is of interest to consider that - underlying their access to a set of privileged social destinations individuals are ranked in descending order of their relative level of social opportunities. This fictitious ordered set may be divided into equal subsections (i.e. opportunity intervals, as deciles: the first $10 \%$ of the population, the following $10 \%$ etc.) This can be associated with a theoretical model enabling the ordered set to be subdivided as far as one wants. Let consider the proportion of individuals of a given social origin $C_{i}$ in each of the small subsections of the ranked population. This distribution of individuals of $C_{i}$ origin may be approximated by a continuous model defined by the function $y=f(x)$. For $x$ varying between 0 and $1, f(x)$ represents the (theoretical) proportion of individuals of $C_{i}$ origin composing the subsection $(x, x+d x)$ as the base of the subsection $d x$ approaches zero.

As $x$ and $f(x)$ vary between 0 and 1 , the curve is traced within a square. In addition the total area beneath the curve is equal to the sum of each of the subsections $d x$ which divide the population multiplied by the proportion $f(x)$ of individuals of $C_{i}$ origin making up that population. It is thus equal to the proportion $\mathrm{m}_{\mathrm{i}}$ of individuals of $C_{i}$ origin in the total population. The area complementing that under the curve corresponds to the proportion $\left(1-m_{i}\right)$ of individuals who are not of $C_{i}$ origin in the total population (cf. figure 1). 


\section{Figure 1}

\section{Continuous distributions of opportunities}

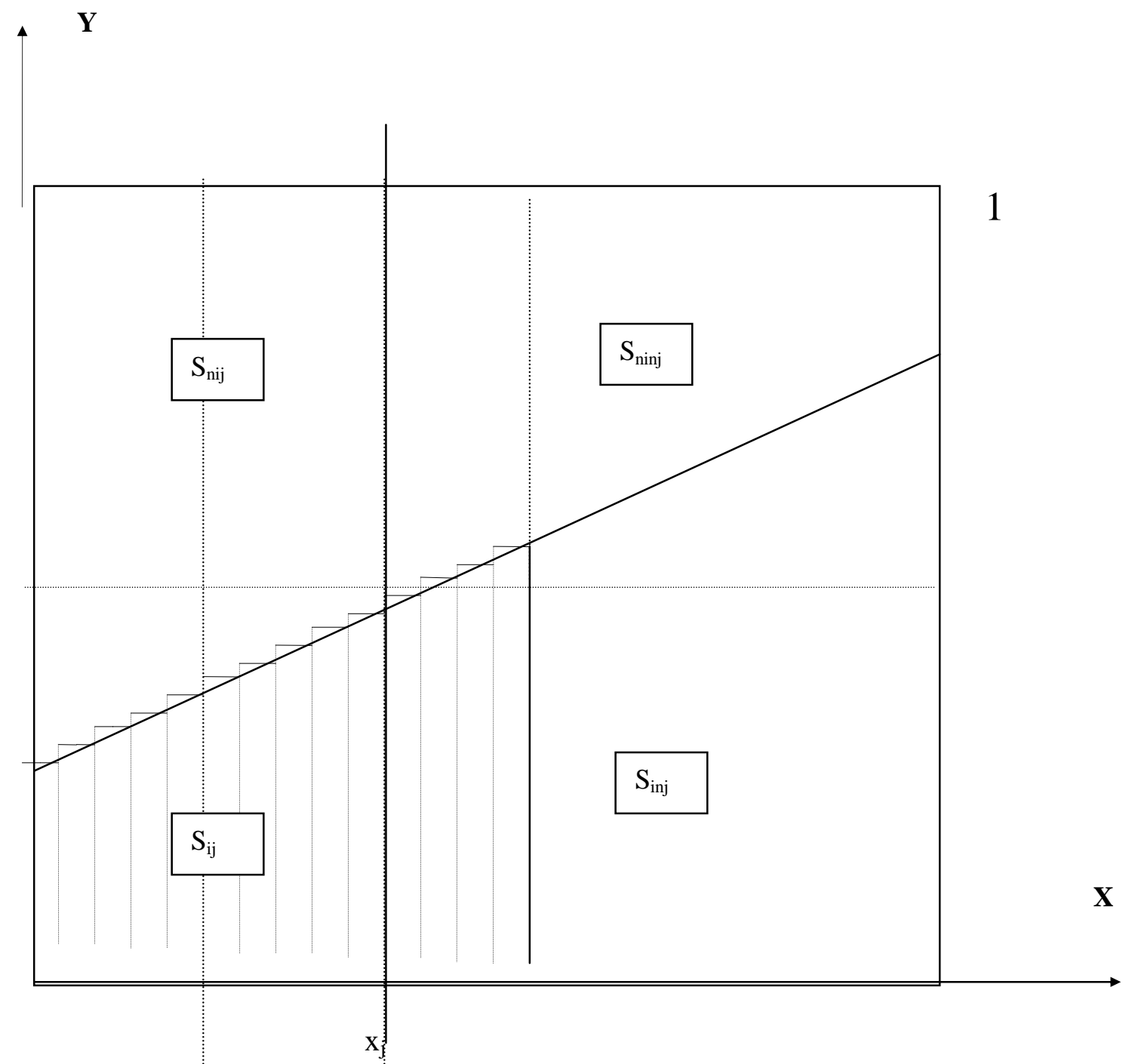

In a context in which social destinations are totally independent of social origins, the curve in question would be the horizontal straight line $y=m_{i}$. In each portion $d x$ of the population having differentiated social opportunities, there would be a proportion $\mathrm{m}_{\mathrm{i}}$ of individuals of $C_{i}$ origin, this 
proportion being equal to their representation in the population as a whole. On the other hand, in a context with full inequality of opportunity, if for instance $C_{i}$ is a non-privileged category, the curve in question would be aligned on the vertical axis $\mathrm{x}=1-\mathrm{m}_{\mathrm{i}}$. Here, all individuals who are not of $C_{i}$ origin would make up all the first $d x$ portions of the population, represented by a rectangle the area of which would correspond to the portion $\left(1-m_{i}\right)$ of individuals who are not of $C_{i}$ origin in the population as a whole.

In the general case of a stratified population in which the social opportunities of individuals are, statistically speaking, as limited as their social origins are modest, the curve $y=f(x)$ is a globally monotonous function. If individuals are ranked in descending order of their relative level of social opportunities, it is an increasing function for non-privileged categories (in the first $d x$ portions of the population, individuals of non-privileged origin tend to be under-represented, whereas they tend to be over-represented in the last portions) and a decreasing function for privileged categories. Figure 2 and figure 3, which show rates of respectively lower manual origin (US) and working class origin (France) in interquintiles intervals of the occupational stratification, give some idea of these distributions. However the distribution of origin categories (lower manual and working-class) in interquintiles intervals is limited here by the statistical categories of social destinations. 


\section{Figure 2}

Representation individuals of lower manual origin in social stratification in USA (not including agricultural professions) Men in Labor Force Aged 21-64 (1973)

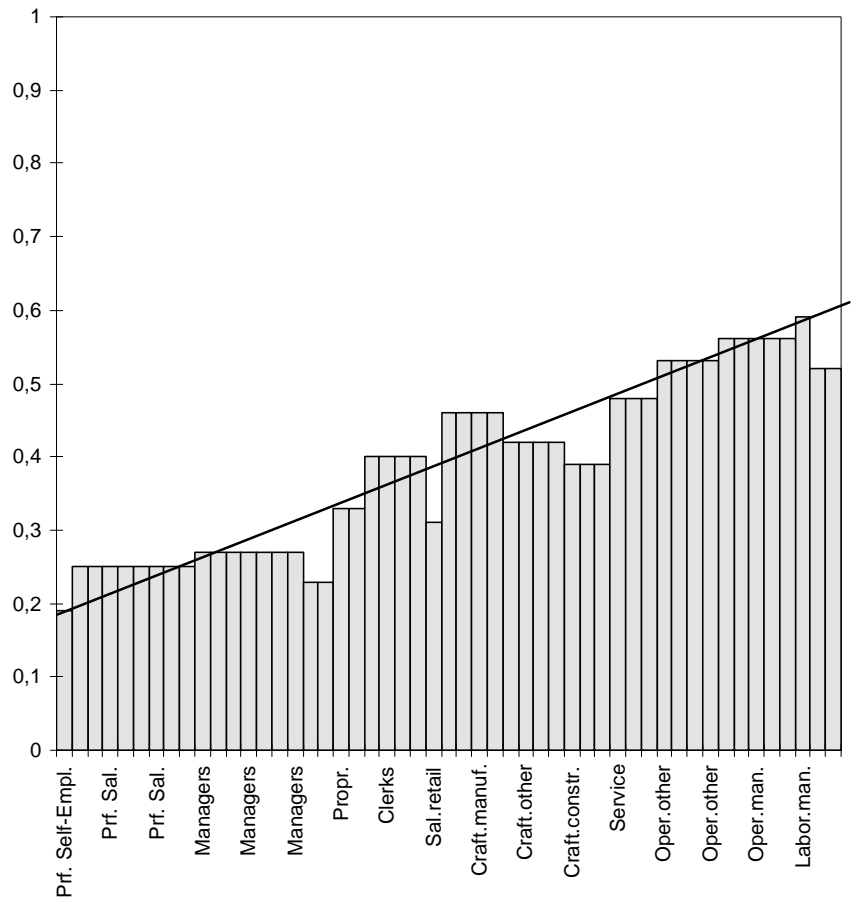

Rates of individuals of lower manual origin

Source: Featherman and Hauser 1978, Table p.535 
Figure 3

Representation of individuals of working-class origin in social stratification in France (not including agricultural professions)

Men in Labor Force Aged 30-55 (1993)

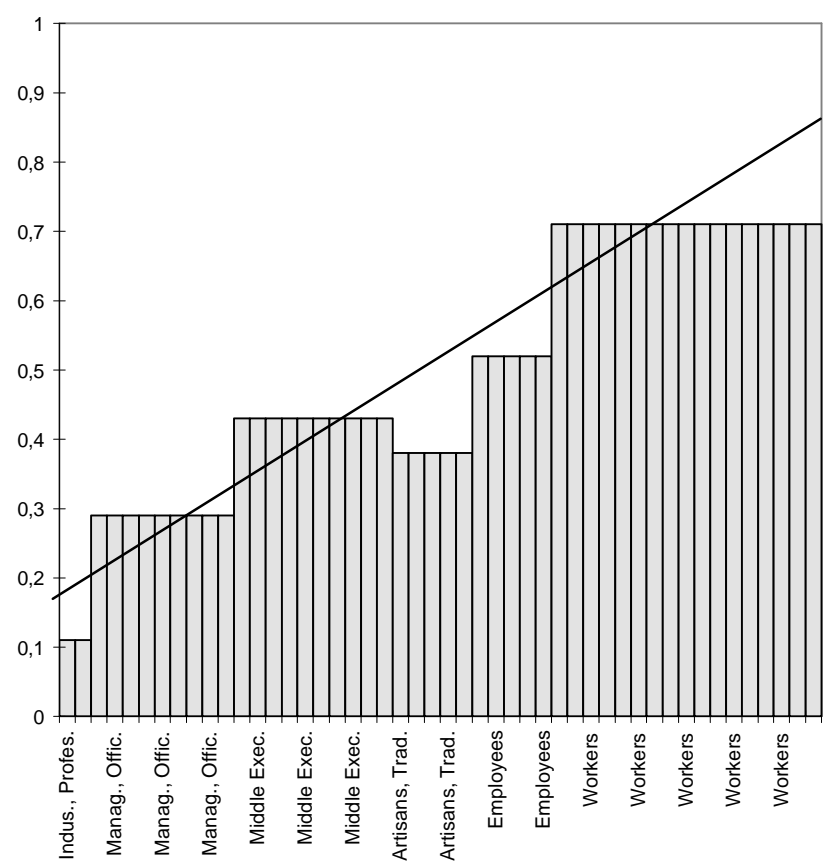

Rates of individuals

of working class origin

Source: French National Institute of Statistics and Economic Studies (INSEE)

\subsection{Definition of the coefficients of opportunity inequality}

Let one distinguish a set of privileged social positions and measure the inequality of opportunity of access to this set. For that let one define a model of the opportunity distribution of individuals from a given category $C_{i}$ using a $\left(d_{i}\right)$ straight line $y=a_{i} \times x+b_{i}$.

The $a_{i}$ coefficient corresponds to the continuous and linear opportunity distribution which would shows the observed ratio between those of $C_{i}$ origin who accede to the privileged social positions and those who do not ${ }^{8}$. As the area under the straight line is equal to the proportion $m_{i}, b_{i}=m_{i}-a_{i} / 2$.

The slope $\left(a_{i}\right)$ of the line is a coefficient of inequality of social opportunity related to the $C_{i}$ category. It indicates the (algebraic) average number of extra portions $d x$ of individuals of $C_{i}$ origin per extra portion $d x$ of the population ranked in descending order of social opportunities. If $C_{i}$ is a non-privileged 
category, $a_{i}>0$ and if $C_{i}$ is a privileged category, $a_{i}<0$. As this coefficient is based on a fixed reference mark of the relative positions reached by individuals, it is not affected by structural mobility. It thus reflects the social selection process net results.

\subsection{Calculation and properties}

In order to calculate $a_{i}$ for each category $C_{i}$ under consideration, it is possible to use the value of the rate of access $x_{i j}$ of $C_{i}$ to the set of privileged social positions $C_{j}$, as follows:

$$
a_{i}=\frac{2 \times m_{i} \times\left(x_{j}-x_{i j}\right)}{\left(1-x_{j}\right) \times x_{j}}
$$

The $a_{i} / 2$ coefficient is calculated as a regression coefficient between two dummy variables (access to $C_{j}$ being the independent variable and belonging to $C_{i}$ the dependent variable).

When $\frac{\left|a_{i}\right|}{2}>m_{i}$ or $m_{i}>1-\frac{\left|a_{i}\right|}{2}$, the straight line $\left(d_{i}\right)$ intersects the base or the top of the square.

In this case the variation interval of the $a_{i}$ coefficient depends on $m_{i}$. Therefore, $a_{i}$ does not represent anymore an intrinsic coefficient of inequality of opportunity.

In the general case, when we have $\frac{\left|a_{i}\right|}{2} \leq m_{i} \leq 1-\frac{\left|a_{i}\right|}{2}$, the following properties are determined.

(1) Let $C_{i}$, i varying from 1 to $\mathrm{n}$, designate $\mathrm{n}$ distinct social categories and $a_{i}$ the respective slopes of the straight lines representing relative social opportunities distributions of individuals originating in these categories. As the values $a_{i}$ represent the (algebraic) average number of extra portions of individuals of $C_{i}$ origin per extra portion $d x$ of individuals of the overall population ranked according to the descending order of individuals' social opportunities, we have:

$$
\sum_{i} a_{i}=0
$$

The zero-sum expresses an idea contained in the 'exchange', 'circulation' or 'pure' mobility concepts as they are composed by flows which cancel each other.

(2) If social categories are aggregated, the slope of the line characterizing the distribution of social opportunities for individuals coming from the aggregated categories is equal to the sum of the slopes of the lines characterizing the social opportunities distributions of each of these categories.

(3) If the coefficient of opportunity of a given social group is $a_{i}$, the coefficient of opportunity of the complementary aggregated social group within the population is $\left(-a_{i}\right)$ The coefficient $a_{i}$ represents the inequality of selection processes results for individuals of a given social group (for instance individuals 
of manual origin) in comparison with individuals from the complementary set within the whole population (for instance individuals of nonmanual origin). These coefficients $\left(a_{i}\right)$ and $\left(-a_{i}\right)$ do not depend on the relative sizes $\left(m_{i}\right)$ and $\left(1-m_{i}\right)$ of the social groups they respectively represent within the population.

\subsection{Relation with Gini coefficients}

The $a_{i}$ coefficients of inequality can be fruitfully compared with Gini coefficients. Let partition the whole population into two complementary groups distinguishing the social origins $\mathrm{Ci}$ with the greatest chances of access to a particular set of favored social destinations and the social origins $\mathrm{C}_{\mathrm{Ni}}$ with the lowest chances of access to these positions. The most significant partition separates social categories with a negative coefficient of inequality and categories with a positive one: $a_{i}$ is maximum.

Let $\left(-a_{i}\right)$ and $\left(+a_{i}\right)$ be the respective coefficients of inequality of two sub-populations as defined above with $a_{i}>0$; let $x_{j}$ be the proportion of the favored social destinations and $m_{i}$ be the proportion of the social origins $\mathrm{Ci}$ within the whole population. The equation of the $\left(d_{i}\right)$ straight line approximating the relative opportunity distribution of the individuals from $C_{i}$ is:

$y=-a_{i} \times x+\left(m_{i}+a_{i} / 2\right)$.

Let $\mathrm{C}_{\mathrm{i}}\left(x_{j}\right)$ be the proportion of the social origins $\mathrm{Ci}$ within the favored social destinations:

$C_{i}\left(x_{j}\right)=\frac{1}{x j} \times\left[1 / 2 \times\left(-a_{i}\right) \times x_{j}^{2}+\left(m_{i}+a_{i} / 2\right) \times x_{j}\right]=-a_{i} / 2 \times x_{j}+m_{i}+a_{i} / 2$

It can be easily demonstrated ${ }^{9}$ that the Gini coefficient $\mathrm{G}_{\mathrm{ij}}$ in this case distinguishing two social subgroups $C_{i}$ and $C_{N i}$ is $G_{i j}=C_{i}\left(x_{j}\right)-m_{i}$

Then we have the following relation:

$G_{i j}=a_{i} / 2 \times\left(1-x_{j}\right)$

This relation consistently expresses these coefficients relative significance:

- the Gini coefficient increases with $a_{i}\left(a_{i}>0\right)$;

- the Gini coefficient tends towards zero when $a_{i}$ tends towards zero, i.e. when opportunities of access to the favoured social destinations tend to be equalized within the population;

- the Gini coefficient tends towards zero when $x_{j}$ tends towards 1, i.e. as the proportion $x_{j}$ of the set of favoured social destinations increases within the population.

- the relation between the coefficient of inequality $a_{i}$ and the Gini coefficient does not depend on the value of $m_{i}$. 


\subsection{Relations with odds ratios}

Let, as above, $x_{j}$ be the proportion of favoured social positions $\left(C_{j}\right)$ offered on the labor market, and let the cumulative (marginal) odds ratio $\theta_{i j}$ establish the comparative chances of individuals originating in one social category $C_{i}$, as opposed to individuals coming from the rest of the population $C_{N i}$ of gaining access to the set of social positions $\left(C_{j}\right)$ rather than the complementary set of social positions $\left(C_{N j}\right) . \theta_{i j}$ is equal to the ratio between areas $\left(\mathrm{S}_{\mathrm{ij}} / \mathrm{S}_{\mathrm{iNj}}\right) /\left(\mathrm{S}_{\mathrm{Nij}} / \mathrm{S}_{\mathrm{NiNj}}\right)$. Such a ratio may be expressed, according to the variables at play (cf. figure 1), by the following formula:

$$
\theta_{i j}=\frac{a_{i}\left(1-x_{j}\right)+2\left(1-m_{i}\right)}{-a_{i}\left(1-x_{j}\right)+2 m_{i}} \times \frac{a_{i} x_{j}+2 m_{i}}{-a_{i} x_{j}+2\left(1-m_{i}\right)}
$$

It can be shown that, given $m_{i}$ et $x_{j}$, there exists a unique pair $\left[a_{i}, b_{i}\right]$ that reproduces the value of $\theta_{i j}{ }^{22}$

The ratio $C_{i j}$ of social opportunities for a definite category $C i$ is equal to the ratio of areas $\left(\mathrm{S}_{\mathrm{ij}} / \mathrm{S}_{\mathrm{iNj}}\right)$ (cf. figure 1).

As $\theta_{i j}=C_{i j} \times \mathrm{S}_{\mathrm{NiNj}} / \mathrm{S}_{\mathrm{nij}}, \theta_{i j}$ and $C_{i j}$ are linked by the relation :

$$
\theta_{i j}=\frac{C i j \times(1-m i-x j+C i j-x j \times C i j)}{x j+x j \times C i j-C i j \times m i}
$$

$C_{i j}$ is the positive root of a quadratic equation which always admits a positive and a negative root, and $a_{i}$ and $C_{i j}$ are linked by the relation:

$$
a_{i}=\frac{2 \times m_{i}}{1+C_{i j}} \times\left[\frac{1}{1-x_{j}}-\frac{C_{i j}}{x_{j}}\right]
$$

and $b_{i}=m_{i}-a_{i} / 2$

Thus, given $m_{i}$ and $x_{j}$, there exists a unique pair, $\left[a_{i}, b_{i}\right]$ that reproduces the value of $\theta_{i j}$. So we can write $\theta_{i j}=g\left(a_{i}, m_{i}, x_{j}\right)$. In this formula, $\left(m_{i}\right)$ depends on the composition of social origins within the population, $\left(x_{j}\right)$ depends on the structure of the labor market and $\left(a_{i}\right)$ represents the inequality of social opportunity coefficient for individuals of $C_{i}$ origin. Within the present theoretical framework, the cumulative odds ratio $\theta_{i j}$, and all local odds ratios comparing origin and destination social categories two by two, are functions of inequality of opportunity distribution and of marginal distributions ${ }^{10}$. Let take for instance the case of an hypothetical society divided into three categories A, B and C. Between 
two periods P1 et P2, let the relative social opportunity distributions for individuals from the different categories remain absolutely stable (these distributions are linear with the respective inequality of opportunity coefficients of $-0,4,-0,2$ et $+0,6$ ), the distribution of social origins within the population remaining unchanged. Let the only varying values be those of social destinations. Then, it can be observed, in the empirical case outlined in Table 1, that all the local odds ratios decrease (cf. Table 2) ${ }^{11}$. This example shows that the variation of all the local odds ratios in one direction does not prove that there is a correlative variation of opportunity inequality when referring to a fixed reference mark of relative opportunity distributions.

\section{Table 1}

Hypothetical mobility tables for periods $P 1, P 2$

P1

\section{Destination}

\begin{tabular}{|c|c|c|c|c|c|}
\hline & & A & B & $\mathrm{C}$ & \\
\hline \multirow{4}{*}{ Origin } & A & 7200 & 11000 & 1800 & 20000 \\
\hline & B & 11600 & 25500 & 12900 & 50000 \\
\hline & $\mathrm{C}$ & 1200 & 13500 & 15300 & 30000 \\
\hline & & 20000 & 50000 & 30000 & 100000 \\
\hline
\end{tabular}

P2

\section{Destination}

\begin{tabular}{|c|c|c|c|c|c|}
\hline & & A & B & $\mathrm{C}$ & \\
\hline \multirow[t]{4}{*}{ Origin } & A & 10200 & 4800 & 5000 & 20000 \\
\hline & B & 17100 & 10400 & 22500 & 50000 \\
\hline & $\mathrm{C}$ & 2700 & 4800 & 22500 & 30000 \\
\hline & & 30000 & 20000 & 50000 & 100000 \\
\hline
\end{tabular}


Table 2

Local odds ratios for periods $P 1, P 2$ and variation rates between $P 1$ and $P 2$

\begin{tabular}{|c|c|c|c|}
\hline $\begin{array}{l}\begin{array}{l}\text { Local odds } \\
(\mathrm{i}<\mathrm{j})\end{array} \\
\end{array}$ & P1 & $\mathrm{P} 2$ & $\mathrm{P} 1 / \mathrm{P} 2$ \\
\hline$\Theta^{A B}{ }_{A B}$ & 1.44 & 1.29 & 1.11 \\
\hline$\Theta_{A B}^{B C}$ & 5.12 & 2.92 & 1.75 \\
\hline$\Theta^{A B}{ }_{B C}$ & 3.09 & 2.08 & 1.49 \\
\hline$\Theta^{B C}{ }_{B C}$ & 2.24 & 2.17 & 1.03 \\
\hline
\end{tabular}

\subsection{Discussion}

Let summarize the following hypotheses mentioned above:

(i) Social destinations can be divided into two complementary social categories $\left(C_{j}\right)$ and $\left(C_{N j}\right)$, each of which represents a set of social positions respectively more and less privileged;

(ii) Relative opportunities of access to a set of privileged social categories $\left(C_{j}\right)$ may be measured on the basis of a continuous scale with equal distances from top to bottom at all points of time.

(iii) The distributions of relative social opportunities for individuals from different social origins can be associated with continuous theoretical models which reveal the inequality of social opportunity structure underlying observed mobility.

(iv) The inequality of social opportunity of these distributions may be measured using straight lines $\left(d_{i}\right)$ of respective slopes $\left(a_{i}\right)$.

One condition of empirical relevance of the defined opportunity distributions is the preference of individuals for each of the positions in a set $\left(C_{j}\right)$ relative to each of the positions of a complementary set $\left(\mathrm{C}_{\mathrm{Nj}}\right)$. Such a dichotomy is apparent when inequality of opportunity refers to access versus non access to a specific social good $(G)$. Here, formally, the social good at stake is access to the set $\left(C_{j}\right)$ of privileged social positions and inequality refers to the continuous opportunity of access distributions underlying actual access. In addition, if there is a variation, from one period to another or from one society to another, in the 'distances' between the two sets of social destinations $\left(C_{j}\right)$ and $\left(C_{N j}\right)$ as a result of changes in the criteria which set them apart, for example income, then preferences tend to a greater or lesser 
degree to be influenced by a number of external factors. Analysis of both horizontal and vertical mobility will thus show a greater or lesser degree of openness which may be attributed to such general societal characteristics.

\section{Summary and conclusion}

Contemporary analyses of social mobility have sought to assess the degree of openness of the mobility process in a comparative perspective. However, when social opportunities are identified by social categories, the mobility models define structural or forced mobility which cannot be controlled for without giving rise to insuperable problems of interpretation. Moreover, measurements of the links between origins and destinations which do not control for this forced mobility, such as odds ratios, lack stable significance with regard to the selection process: changes in the distribution of the destination categories affect the links between these categories and the selection process.

To eliminate structural mobility the method developed here refers to a fixed reference mark of relative opportunity distributions of individuals from the various social origins. These opportunity distributions are assumed to underlie observed access to privileged social positions and are associated with continuous theoretical models.

Within this framework, the only hypothesis required relates to the shape of relative opportunity distribution for individuals in each category. Once these shapes are taken into account, and given the table margins, all that remains is to determine those parameters characterizing the distributions in question which would likely reproduce the social destinations observed. Modelling these distributions by the means of straight lines permits comparisons of inequality in the selection process. In the general case mentioned above, the slopes $\left(a_{i}\right)$ of the lines are exclusive of marginal values. As a result this method can help to develop comparative explanations of the mobility process. Within the limit of the hypotheses outlined above, it permits to differentiate the inequality of individual results of the social selection process from observed links between origin and destination categories. In addition it can help to overcome a lot of other research problems as it authorizes comparisons of opportunity inequality in the process of access to any discrete good, at any point of time. Schooling for instance may represent an important area for its application. 


\section{REFERENCES}

Billewicz W.Z. 1955. "Some Remarks on the Measurement of Social Mobility" Population Studies 9: 96100.

Blackburn, R.M., Marsh, C. 1991. "Education and social class:revisiting the 1944 Education Act with fixed marginals" British Journal of Sociology 42: 507-536.

Blackburn R.M., K.Prandy. 1997. “The Reproduction of Social Inequality” Sociology 31 (3): 491-509.

Blau P.M. O.D.Duncan.1967. The American Occupational Structure. New York: Wiley.

Boudon, R., 1972. A Note on Social Inequality and Immobility Measurement. Quality and Quantity 6 (1), 17-35.

Boudon R. 1973. Mathematical Structures of Social Mobility. Amsterdam: Elsevier.

Cherkaoui, M. 2003. "The Individual and the Collective" European Review, 11 (4): 489-504.

Duncan, O. D. 1966. "Methodological Issues in the Analysis of Social Mobility" pp.51-97 in: Smelser, N.J., Lipset, S.M., (Eds.) Social Structure and Mobility in Economic Development Chicago: Aldine

Featherman, D. L., Hauser, R.M. 1978. Opportunity and Change. New York: Academic Press.

Glass, D. V. 1954. Social Mobility in Britain : Routledge.\& Kegan Paul.

Goldthorpe, J. H. (in collab. with Llewellyn, C., Payne, C.) 1980. Social Mobility \& Class Structure in Modern Britain Oxford: Clarendon Press.

Goldthorpe, J.H. 2000. On Sociology, Numbers, Narratives, and the Integration of Research and Theory . Oxford: Oxford University Press.

Harrison R.J. 1988. "Do odds ratios really control for the availability of occupational positions in status contingency tables?" European Sociological Review 4 (1): 65-79.

Jarvie, I. C. 1972. Concepts and Society. Boston: Routledge \& Kegan Paul.

Lang J.B., Eliason S.R. 1997. “Application of Association-Marginal Models to the Study of Social Mobility" Sociological Methods \& Research 26 (2) : 183-212.

Matras J. 1960. "Comparison of Intergenerational Occupational Mobility Patterns, An Application to the Formal Theory of Social Mobility" Population Studies 14:163-169.

McClendon, M.J. 1977. "Structural and Exchange Components of Vertical Mobility” American Sociological Review 42:56-74.

Miller S.M. 1960. “Comparative Social Mobility” Current Sociology 27 (9): 1-89.

Nobel T. 1979 “In Pursuit of Pure Mobility” Sociology 13: 483-495.

Persson G. 1977. "Pure Mobility and Pure Exchange Mobility" Quality and Quantity 11: 73-82.

Rogoff, N. 1953. Recent Trends in Occupational Mobility Glencoe: Free Press. 
Sobel, M.E. 1983. "Structural Mobility, Circulation Mobility, and the Analysis of Occupational Mobility: A Conceptual Mismatch” American Sociological Review 29: 16-23.

Sobel, M.E. , M.Hout and O.D. Duncan. 1985. "Exchange, Structure, and Symmetry in Occupational Mobility" American Sociological Review 9: 359-372.

Sobel, M.E., Becker M.P., Minick S.M. 1998. “Origins, Destinations, and Association in Occupational Mobility" American Journal of Sociology 104 (3) : 687-721.

Sorensen A.B. 1977. "The Structure of Inequality and the Process of Attainment" American Sociological Review 42: 965-978.

Tyree A. 1973. "Mobility Ratios and Association in Mobility Tables" Population Studies 27 : 577-588.

Yasuda, S. 1964. “A Methodological Inquiry Into Social Mobility” American Sociological Review 29:1623. 


\section{NOTES}

${ }^{1}$ According to Goldthorpe (2000) this approach "entailed an attempt at partitioning total mobility into two notional components that could actually be identified only at the supra-individual, or macrosocial, level, whereas the mobility table itself was a record of individual cases".

${ }^{2}$ They are known as odds-ratios in the literature. These odds ratios establish the comparative chances of individuals originating in one social category, as opposed to individuals originating in another social category, of gaining access to one social position rather than another.

${ }^{3}$ Their value does not change when we multiply the lines or the columns of a mobility table by a constant.

${ }^{4}$ The log-linear modeling of the data on a contingency table is based on hypotheses on the association structures which link the variables of the table. The results predicted by these models (expected figures position by position) are compared to observed figures.

${ }^{5}$ Later research (Eliason et al. 1997 ; Becker et al. 1998) tends toward displacement in favor of focus on both analysis of 'structural' mobility (defined as some function of the difference between the origin and destination marginal distributions) and 'association' mobility (that evaluates the dependence of individual's destination on individual's origin). These approaches are based on combining models for marginal distributions with models for the patterns of association.

${ }^{6}$ In horizontal mobility analysis, exchanges between two consecutive categories within the social stratification are implicitly equivalent to exchanges between categories far apart. McClendon (1977) critical appraisal is followed here : it is significant that the major categories of socioeconomic classifications are generally ranked according to their average score on a vertical scale.

${ }^{7}$ The problem is not only a practical one. Mc Clendon prefers prestige status scores to percentile ranks for instance, which are only ordinal measures. Nevertheless the simple ranking of individuals meets better the idea of selection process net results. For instance, as Mc Clendon stresses it, any difference in the shapes of the origin and destination distributions as measured by a particular prestige scale will be a structural influence on measured mobility that is not eliminated by using standard scores. 
${ }^{8}$ As mentioned above, there is not an exact correspondence between the opportunity scale defined (which refers to access to a set of privileged categories) and the interquentiles intervals which can be defined on the basis of occupational stratification. The following results (that can be associated to linear distributions) are obtained in the case of US represented on figure 2 and in the case of France represented on figure 3:

US: $\mathrm{a}_{\mathrm{lm}}$ represents the inequality coefficient of lower manual categories;

$\mathrm{a}_{\mathrm{lm}}($ access to upper nonmanual positions $)=0,43$

$\mathrm{a}_{\mathrm{lm}}($ access to nonmanual positions $)=0,41$

$\mathrm{a}_{\operatorname{lm}}($ access to nonmanual or upper manual positions $)=0,41$

France: $a_{w}$ represents the inequality coefficient of working-class categories;

$\mathrm{a}_{\mathrm{w}}($ access to managerial positions $)=0,61$

$\mathrm{a}_{\mathrm{w}}$ (access to managerial or clerical positions $)=0,55$

$\mathrm{a}_{\mathrm{w}}($ access to managerial, clerical or artisans positions $)=0,64$

$\mathrm{a}_{\mathrm{w}}($ access to nonworking-class positions $)=0,66$

${ }^{9}$ The demonstration relies on a calculus of areas knowing that the Gini coefficient is twice the area bounded by the concentration curve and the first bisecting line.

${ }^{10}$ It can also be noted that they become independent of the margins values only when $\mathrm{a}_{\mathrm{i}}=0$, meaning when social origins and destinations are fully independent of one another: their value thereof is then necessarily 1.

${ }^{11}$ In a $n$ by $n$ table, the $\left(n^{2}-n\right)^{2} / 4$ local odds ratios are deducible from $(n-1)^{2}$ independent ones of them (by multiplication 2 by 2). In addition, as four independent odds ratios decrease here, it is the case for all of the nine. 